Research Article

www.jestr.org

\title{
Aerodynamic Characteristics of Individual Ballast Particle by Wind Tunnel Tests
}

\author{
G.Q. Jing ${ }^{1}$, G.X. Liu ${ }^{1}$, J. Lin ${ }^{1}$, J. Martinez ${ }^{2}$ and C.T. Yin ${ }^{3, *}$ \\ ${ }^{I}$ Civil Engineering School, Beijing Jiaotong University, Beijing 100044, China \\ ${ }^{2}$ LGCGM - INSA de Rennes, Université Européenne de Bretagne, EA3913, France \\ ${ }^{3}$ Beihang University, 37 Xueyuan Rd, Haidian Dist, Beijing 100191, China
}

Received 11 January 2014; Accepted 28 April 2014

\begin{abstract}
Ballast flying has been considered as a problem in train aerodynamics with increasing the maximal speed. And this phenomenon seriously threats the safety of train operation. However, aerodynamic characteristics of individual ballast were less studied in the previous literature. This paper describes an investigation of the aerodynamic effect of ballast particles by wind tunnel tests. It considers the nature of the wind and ballast physical characteristics. A simple method for calculating the wind effects by CFD is set out, ballast particles were classified according to their shapes and mass in order to investigate the influence of the wind velocity, wind pressure and other parameters on displacement of ballast particles. Two sets of wind tunnel tests were performed under the conditions that ballast particles were movable and unmovable on the platform respectively. The tests data and reasonable explanations were given, as well as the CFD simulations of individual ballast particles.
\end{abstract}

Keyword: Ballast Flying, Aerodynamics, Wind Tunnel

\section{Introduction}

High-speed railway has been working around the world for decades of years. Ballast bed is one of the most important approaches of the high speed railway. Ballast flying has been considered as a problem in train aerodynamics since the 1980's. The trains produce powerful airflows that increase the ballast flying occurrence, resulting in lots of issues [1], [2], [3]. Obvious evidences of ballast flying such as damaging wheel, breaking glasses at station, and injuring acoustic screen have frequently been reported [2]. The flying ballast particles may hit the bottom of train body and make it distorted. If the ballast fall onto the rail tread, the interaction between the wheel and rail surface may lead to derail for the worst case [4]. Ballast flying is becoming an assignable factor of threatening the train operation and limiting the speed of ballasted high-speed trains. It is of great importance to focus on the ballast flying topic in order that it will not be the obstacle in the development of the ballasted high-speed railway [5].

When a train runs at high speed, a strong turbulent airflow is induced beneath the train because of the boundary layer on the train surface as well as the perturbation by irregular shapes of train such as protruding bogies and cavity of inter-car. At train speeds from $200 \mathrm{~km} / \mathrm{h}$ to $300 \mathrm{~km} / \mathrm{h}$, strong airflow at speed of between $20 \mathrm{~m} / \mathrm{s}$ and $50 \mathrm{~m} / \mathrm{s}$ is induced in the vicinity of train and track. Then it enforces the ballast on the track to start roll along the track to bound away [3], [6].

\footnotetext{
*E-mail address: chuantao.yin@buaa.edu.cn

ISSN: 1791-2377 @ 2014 Kavala Institute of Technology. All rights reserved.
}

The explanations of this phenomenon have been achieved from two points of view [3]. The first one is ballast-flying by strong wind in the vicinity of train and track. The other one is ballast-flying by impact of accreted snow and ice from train under-floor. This sporadic, discrete phenomenon is difficult to characterize by in-situ tests, therefore statistic observations on ballast particle wind tunnel tests are required to determine solutions to reduce this kind of phenomenon, as well as risk assessment [7].

It is clearly that ballast flight is a sporadic phenomenon which is difficult to predict or to characterize under real conditions [8], [9], [10]. It is not clear the relevance and devotion of that these results obtained under idealized conditions for the situation on real track bed [7], [11]. However, characteristics of individual ballast particles tested in wind tunnel have been proved of significance, especially with the variation of wind velocity. The wind velocity can be changed by the control panel. Meanwhile the pressure on ballast particles and the displacement of ballast particles can be obtained by the wind pressure transducer and the displacement transducer respectively. In order to analyze the relationships between these parameters and the wind velocities, two sets of tests were performed. Firstly, the ballast particles were adhered to the test platform. The wind pressure data were recorded as the wind velocity changes. Secondly, the ballast particles without constraint were placed on the platform. The critical wind velocities at which the ballast particles start to move were determined.

Finally, the CFD numerical simulation method is employed, the results of wind tunnel tests were verified and more characteristics such as wind pressure distribution and wind pressure changes were investigated. 


\section{Method and material}

\subsection{Balance equilibration method}

In the past research [1], G.Q. Jing gave the detailed descriptions about the ballast flying mechanism in formulas. Simple mechanics models can be laid down to detect the key parameters. Herein, the ballast particles are analyzed and characterized by the $m g, F_{i}, F_{w}, a_{T}$. Where $m g$ is gravity force by mass, $F_{i}$ is ballast particle interlock force, $F_{w}$ is wind force resulted by high speed train acted on ballast effective surface $\left(\mathrm{A}_{\mathrm{e}}\right)$, and $F_{a}$ is ballast acceleration due to ballast bed vibration, illustrated as Fig. 1.

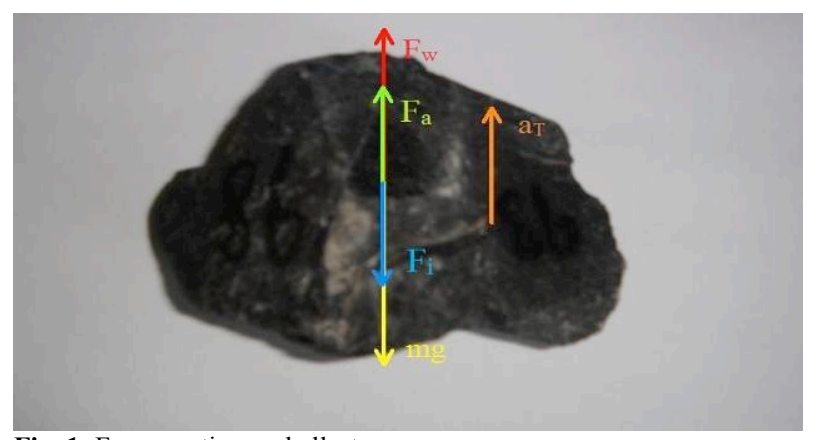

Fig. 1. Forces acting on ballast

Based on d'-Alembert principle, the equation for ballast particle balance is as following:

$$
F_{w}+F_{a}=m g+m a_{T}+F_{i}
$$

It is very complicated to compute the viscous force on the irregular surface of the ballast. Generally, we take the wind pressure coefficient $\alpha$, and high speed train resulted wind force can be calculated as following:

$$
F_{w}=\alpha \int_{0}^{A} f(A) d A
$$

The following result is obtained from above formulas with an inference procedure:

$$
a_{T}=\frac{\alpha \int_{0}^{A} f(A) d A}{m}-(g-a)
$$

$$
a_{T}=\frac{\alpha f(A)}{\rho \int_{z_{1}}^{z_{2}} A(z) \mathrm{d} z}-(g-a) \mathrm{z}
$$

$$
a_{T}=\frac{\alpha}{\rho \int_{z_{1}}^{z_{2}} d z}-(g-a)
$$

Where $\rho$ is density of ballast particle.

The formula shows a brief quantized relationship between wind effects and vibration of ballast. Some practical information could be inferred from the above formula, such as track structure optimization, for example, the heavier ballast could be used in the renovation of existing railway lines or in the building of new ones. But the above method only a theoretical equation, and the specific parameters or data should be determined. The following work was developed to determine the key parameters, such as the wind force, ballast aerodynamic characteristics etc.

\subsection{Wind tunnel Tests}

The ballast surface transport is a key process of ballast flight or mitigation, which is characterized by the particles move from ballast bed surface. In this stage the ballast particle is accelerated in the $\mathrm{x}$ direction by the aerodynamic load, which could be analyzed by wind tunnel tests. A case in point, in 2008, H.B. Kwon of South Korea conducted a series of tests to investigate the ballast flying mechanism [2]. In the wind tunnel tests, the relation between wind velocity and ballast flying displacement was preliminary investigated. The wind velocity at which ballast started to move and was totally blown out was obtained. They also measured the wind velocity in the field condition and gained some wind velocity resulted from the high speed train. But the paper did not take into account the wind boundary effect, and the platform was not elevated to some height to reduce the boundary effects. They also pointed out that more studies need to be done to determine and demonstrate their conclusions.

The wind tunnel in Beijing Jiaotong University is a return-flow duplex wind tunnel. The scale of high speed section is $3.0 \mathrm{~m} \times 2.0 \mathrm{~m} \times 15.0 \mathrm{~m}$ and the low speed section is $5.2 \mathrm{~m} \times 2.5 \mathrm{~m} \times 14.0 \mathrm{~m}$, and the maximum velocity is $40 \mathrm{~m} / \mathrm{s}$.

The boundary layer effect of airflow tells that the speed of the wind at the bottom is low and unstable. In terms of the tests performed by Canadian researchers [7], the ballast should be placed on a platform away from the bottom of the wind tunnel. In this paper, a simple test was conducted in order to determine the effect of boundary. Measurements were carried out by three wind velocities in the center of the turntable. Fig. 2 shows the change of wind velocity away from the floor of the wind tunnel for 3 different wind velocities. It shows that the boundary layer effect should not be neglected below the height of $350 \mathrm{~mm}$.

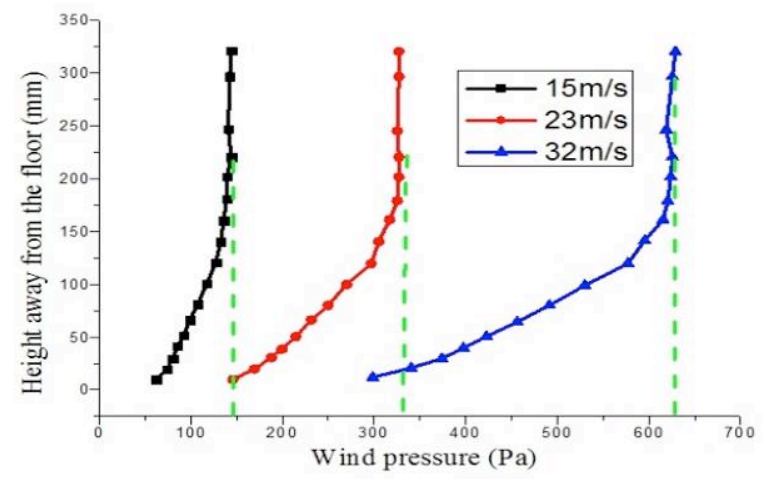

Fig. 2. Boundary layer effect of wind tunnel

\subsection{Ballast samples}

In the wind tunnel tests, ballast samples of granite rock were used, and then they were numbered, weighed and punched into a small hole with an aim to measure the wind pressure on surface of ballast particles. The ballast particles were divided into three classical shapes in each group, namely A (spherical) B (half-spherical) and C (flat) respectively [2]. Number was assigned for different mass of ballast particles. 
G.Q. Jing, G.X. Liu, J. Lin, J. Martinez and C.T. Yin

Journal of Engineering Science and Technology Review 7 (2) (2014) 137 - 142

As the number increases, the particle size decreases. Taking into account the difficulty in punching a hole for the ballast particles, 9 ballast particles were punched with holes for the measurement of wind pressure. Part of the ballast particles are listed in Table 1.

Table 1 Ballast used in the wind tunnel test

\begin{tabular}{c|c|c|c}
\hline \multicolumn{2}{c|}{ Ballast ID } & $\begin{array}{c}\text { Mass } \\
\text { (g) }\end{array}$ & $\begin{array}{c}\mathbf{A}_{\mathbf{e}} \\
\left(\mathbf{c m}^{2}\right)\end{array}$ \\
\hline \multirow{4}{*}{ Spherical } & A1 & 427 & 21.0 \\
& A2 & 379 & 28.2 \\
& A3 & 367 & 22.2 \\
& A4 & 343 & 27.8 \\
Half-Spherical & B1 & 404 & 19.2 \\
& B2 & 307 & 29.5 \\
\cline { 1 - 1 } Flat & B3 & 270 & 22.2 \\
& B4 & 263 & 16.8 \\
& C1 & 264 & 14.8 \\
& C2 & 223 & 17.0 \\
& C3 & 203 & 32.0 \\
& C4 & 178 & 26.8 \\
\hline
\end{tabular}

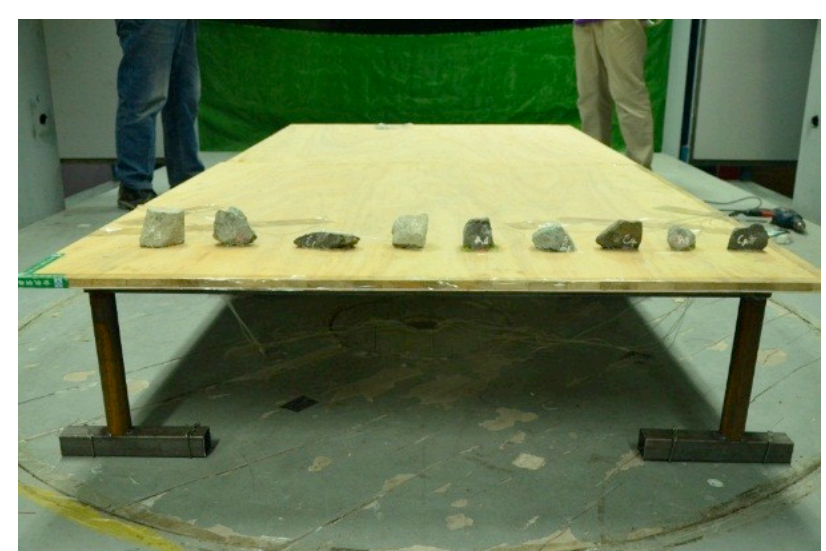

Fig. 3. Platform height of $350 \mathrm{~mm}$

\subsection{Test procedure}

During the first set of tests, the ballast particles adhered to the platform in a row perpendicular to the wind direction using the glue, and the air pressure transducer adhered to the surface of ballast particle.

After sealing off the wind tunnel, the speed of wind increases gradually. According to the empirical value, the air pressure begins to be recorded at the speed of $10 \mathrm{~m} / \mathrm{s}$. and the speed of the wind were increased by $3 \mathrm{~m} / \mathrm{s}$ each step meanwhile the wind pressure was recorded respectively.

In the second set of tests, more ballast particles were placed on the platform and the ballast used in the first set of tests were dismounted and placed on the platform. Three rows of ballast have been set on the test platform of wind tunnel perpendicular to the wind direction.

The critical wind velocity $\left(\mathrm{V}_{\mathrm{c}}\right)$ at which the ballast started to move were recorded when the wind velocity increased. The wind velocity increased until $30 \mathrm{~m} / \mathrm{s}$ taking the equipment safety into consideration. Then the displacement of ballast were measured and recorded.

\section{Results and Analysis}

\subsection{Wind Pressure Testing}

Fig. 4 showed that the wind pressure was positively related with the wind velocity especially when the wind velocity is less than $22 \mathrm{~m} / \mathrm{s}$. then the wind pressure of ballast numbered
A7 increased faster, it was guessed that the friction and concave-convex of the ballast played a role for the rising. This case reflects the uncertainty of ballast flying and it would be further studied.

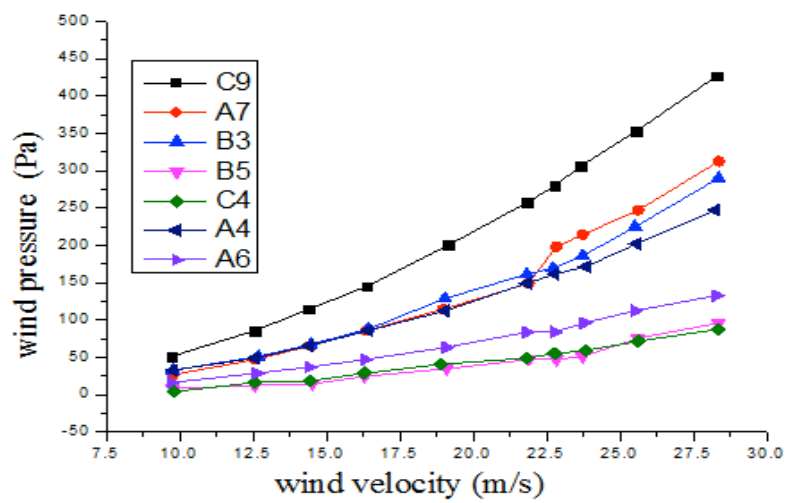

Fig. 4. Wind pressure vs. wind velocity

\subsection{Critical Wind Velocity and Ballast Displacement}

Fig. 5 shows the displacement change of ballast particles in the wind tunnel test. All information and data recorded for the unfixed ballast wind tunnel test are listed in Table 2. In all cases, most of the ballast particles started to move at the velocity of less than $25 \mathrm{~m} / \mathrm{s}$, indicating that high speed train aerodynamics leads to ballast particle motivation. In practice, train wind is one of the most important aspects related to train speed [1]. There have been extensive studies to understand the effect of aerodynamic forces acting on the railway track, where the key aerodynamic factor is wind speed, since the wind is directly related to the speed of the train. HSR operators worldwide suggest that ballast flight have appeared to occur at speed above $260 \mathrm{~km} / \mathrm{h}$, which the wind speed is usually between $20-30 \mathrm{~m} / \mathrm{s}$.

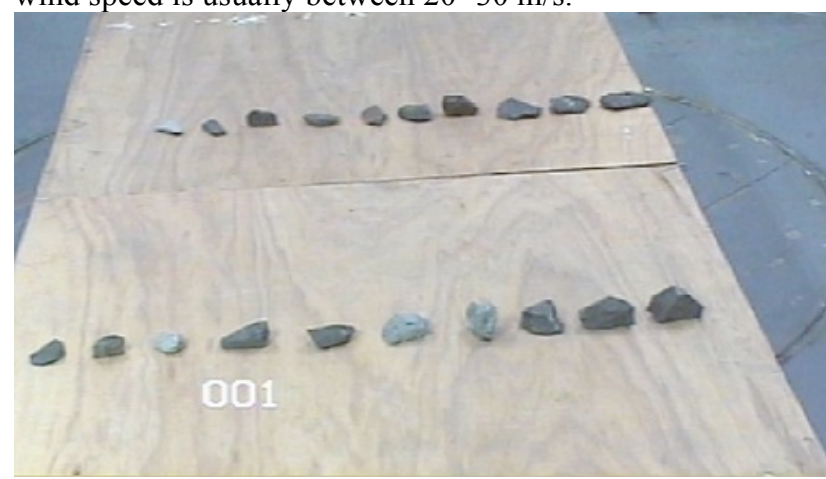

a)

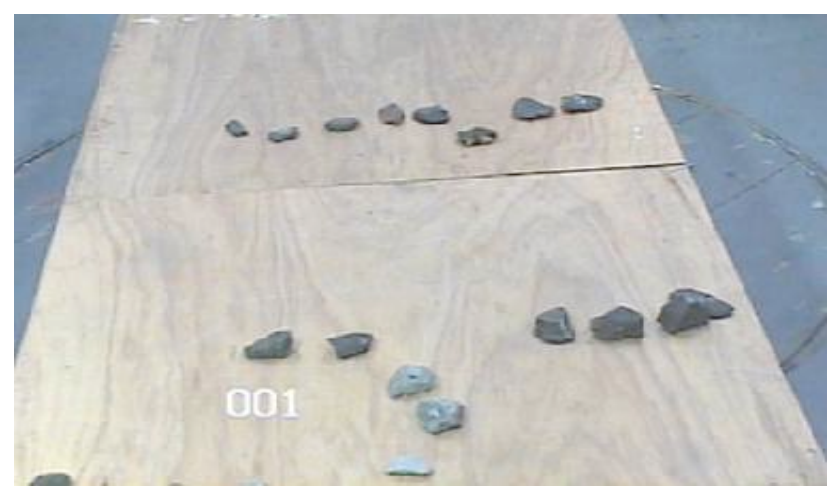

b)

Fig. 5. Displacement of unfixed ballast during wind tunnel test (a: Before test, b: After test) 
G.Q. Jing, G.X. Liu, J. Lin, J. Martinez and C.T. Yin

/Journal of Engineering Science and Technology Review 7 (2) (2014) 137 - 142

Table 2. Wind tunnel test of unfixed ballast

\begin{tabular}{|c|c|c|c|c|c|}
\hline \multicolumn{2}{|c|}{ Ballast ID } & \multirow{2}{*}{$\begin{array}{c}\text { Mass } \\
\text { (g) }\end{array}$} & \multirow{2}{*}{$\begin{array}{c}\begin{array}{c}\mathbf{V}_{\mathbf{c}} \\
(\mathbf{m} / \mathbf{s})\end{array} \\
27.83\end{array}$} & \multirow{2}{*}{$\begin{array}{c}\begin{array}{c}\mathbf{A}_{\mathrm{e}} \\
\left(\mathbf{c m}^{\mathbf{2}}\right)\end{array} \\
15.33\end{array}$} & \multirow{2}{*}{$\begin{array}{c}\begin{array}{c}\text { Displacement } \\
\text { (cm) }\end{array} \\
0\end{array}$} \\
\hline \multirow{11}{*}{ Spherical } & A1 & & & & \\
\hline & $\mathrm{A} 2$ & 379 & 25.69 & 11.44 & 0 \\
\hline & A3 & 367 & 29.23 & 20.53 & 0 \\
\hline & A4 & 343 & 26.75 & 15.34 & 3 \\
\hline & A5 & 309 & 25.41 & 16.61 & 5.2 \\
\hline & A6 & 271 & 18.95 & 13.55 & 8.7 \\
\hline & A7 & 264 & 17.02 & 15.53 & 12.4 \\
\hline & A 8 & 109 & 15.42 & 10.38 & 0 \\
\hline & A9 & 101 & 19.89 & 9.81 & 19 \\
\hline & A 10 & 77 & 15.76 & 7.00 & 25 \\
\hline & A11 & 64 & 14.20 & 7.80 & 34 \\
\hline \multirow{10}{*}{ Half-spherical } & B1 & 404 & 19.40 & 21.04 & 3 \\
\hline & B2 & 307 & 17.98 & 10.41 & 0 \\
\hline & B3 & 270 & 19.62 & 12.16 & 1 \\
\hline & B4 & 263 & 20.80 & 15.65 & 5 \\
\hline & B5 & 249 & 18.73 & 17.17 & 5.5 \\
\hline & B6 & 222 & 19.61 & 11.38 & 19.6 \\
\hline & B7 & 177 & 18.73 & 8.43 & 4.3 \\
\hline & B8 & 91 & 12.26 & 12.13 & 36 \\
\hline & B9 & 87 & 13.06 & 6.59 & 25 \\
\hline & $\mathrm{B} 10$ & 86 & 21.56 & 9.25 & 47 \\
\hline \multirow{10}{*}{ Flat } & $\mathrm{C} 1$ & 264 & 24.56 & 17.84 & 0 \\
\hline & $\mathrm{C} 2$ & 223 & 17.28 & 13.12 & 0 \\
\hline & $\mathrm{C} 3$ & 203 & 19.95 & 6.34 & 0 \\
\hline & $\mathrm{C} 4$ & 178 & 14.85 & 6.64 & 0 \\
\hline & C5 & 159 & 22.38 & 18.07 & 2.5 \\
\hline & C6 & 123 & 23.87 & 15.77 & 3.6 \\
\hline & $\mathrm{C} 7$ & 116 & 18.07 & 12.89 & 4.5 \\
\hline & $\mathrm{C} 8$ & 75 & 14.97 & 14.71 & 16 \\
\hline & C9 & 69 & 8.58 & 3.21 & 18 \\
\hline & $\mathrm{C} 10$ & 67 & 8.18 & 13.96 & 19.2 \\
\hline
\end{tabular}

Fig. 6 shows that the $V_{c}$ of flat ballast particles at which the ballast particles start to move. Generally speaking, the critical wind velocity increases as the mass increases except two points. It can be drawn that $\mathrm{V}_{\mathrm{c}}$ is less than $30 \mathrm{~m} / \mathrm{s}$ as indicated in Table 2 and Fig. 5. In practice, some ballast flight researcher proposed that a solution defined consists in the heavy solid waste, to simulate the characteristics and performance of the natural ballast while offering greater weight to reduce the probability of ballast mitigation.

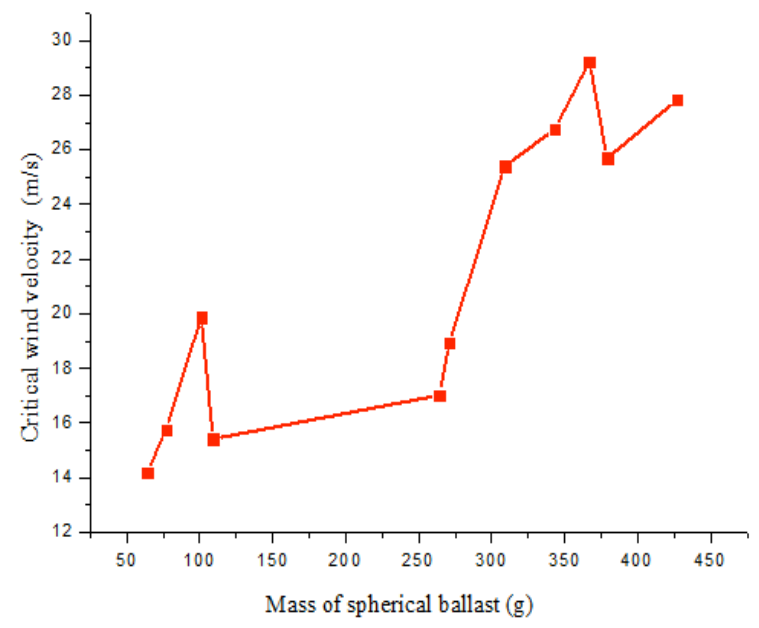

Fig. 6. Critical wind velocities vs. mass of spherical ballast

The data in Table 2 and Fig. 6 shows that the lighter (smaller) ballast particles started to move in a low critical wind velocity in general. But in Fig. 6 , it is clearly that the relationships between critical wind velocities and the ballast mass are not so that exact. However, after ignoring some irregular points we could fit the experimental curves in Fig. 7 with a simple exponential function. Results illustrated that the wind velocity increases as the train speed, the probability of ballast flying rises accordingly. It is very dangerous for the train operation. It leads to a series of damage for the train, rail.

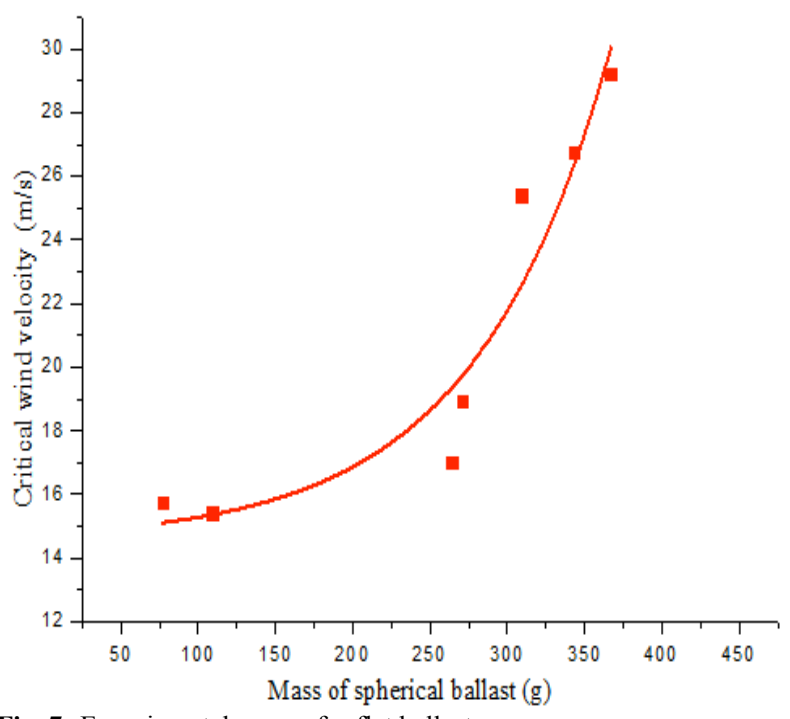

Fig. 7. Experimental curves for flat ballast

The simple exponential function for flat ballast is listed as following:

$y=y_{0}+A e\left(\frac{x-x_{0}}{t}\right)$

Where $x_{0}$ is $-110, y_{0}$ is $14.5, \mathrm{~A}$ is 0.068 , and $\mathrm{t}$ is 88 .

In Table 2 we can come to another conclusion that the displacement has a negative relation with the ballast mass in general. In other words, with most of the cases, the ballast that starts to move earlier could move farther. Fig. 8 showed the experimental data between displacement and mass of flat ballast. We find that the ballast particle displacement is partially inverse proportional to its mass. The fitted curve could be given to describe the relationship in Fig. 9.

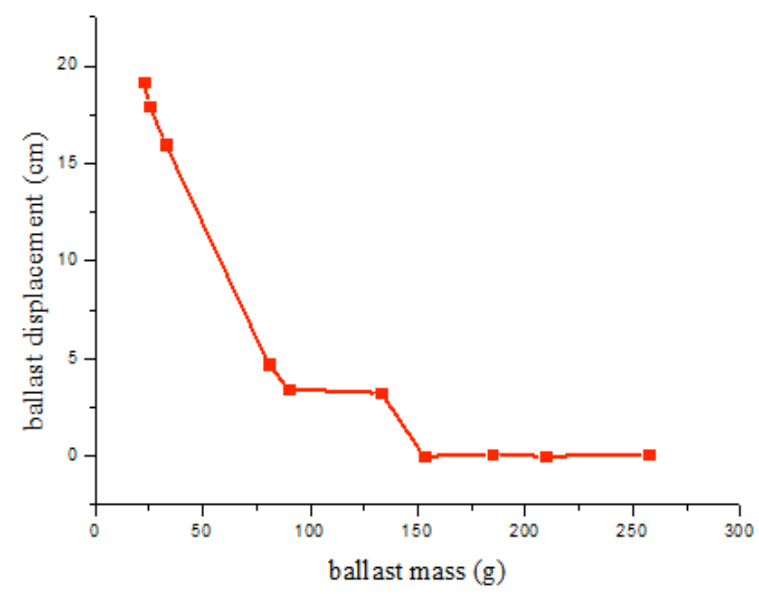

Fig. 8. Displacement vs. ballast mass for flat ballast 
G.Q. Jing, G.X. Liu, J. Lin, J. Martinez and C.T. Yin

/Journal of Engineering Science and Technology Review 7 (2) (2014) 137 - 142

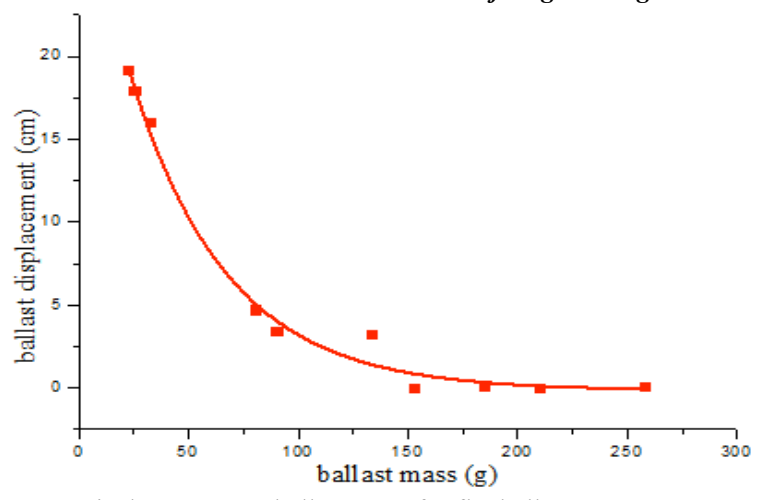

Fig. 9. Displacement vs. ballast mass for flat ballast

A simple exponential function between displacement and mass of flat ballast was given as following:

$$
y=y_{0}+A e^{-x / t}
$$

Where $y_{0}$ is $-0.14, A$ is $32.5, \mathrm{t}$ is 44 .

\subsection{Mechanism of Ballast Flying by CFD}

Numerical investigations describing the aerodynamics and crosswind stability of high speed trains can be found in the literature [7], [8]. The CFD has been used as an important tool for flow assessment and investigation and also to evaluate the effect of variations. In our research, the FLUENT was used to simulate and analyze fluid flow and transmission phenomenon of ballast particle aerodynamics. In this paper, simulation for wind tunnel test was performed. The CFD 3D model for the ballast particle wind tunnel test was built and analyzed through wind conditions.

\subsubsection{Mesh Design and Boundary Conditions}

The simulation of ballast particle wind tunnel test was aimed to investigate the relationship between wind pressure and wind velocity. The FLUENT 3D model was built by GAMBIT, which ass pre-processing software package. According to the test performed above, the computation domain ranged $3 \mathrm{~m}$ in length, $1.6 \mathrm{~m}$ in width and $0.83 \mathrm{~m}$ in height. The test platform was $1.3 \mathrm{~m} \times 1.2 \mathrm{~m} \times 0.35 \mathrm{~m}$. 9 ballast particles were located on the platform. The surface of flow-inlet was $3.0 \mathrm{~m}$ on $\mathrm{z}$-axis, $2.0 \mathrm{~m}$ far away from the ballast and $1.7 \mathrm{~m}$ away from the platform in case of improper boundary layer effect of airflow. The model was partitioned into unstructured mesh of tetrahedron. The mesh number was 1.16 million, which was determined by finite volume method. Fig. 10 shows the partitioned mesh for the direction of $x-y$ plane. It should be emphasized that the windward sides were simplified into planes.

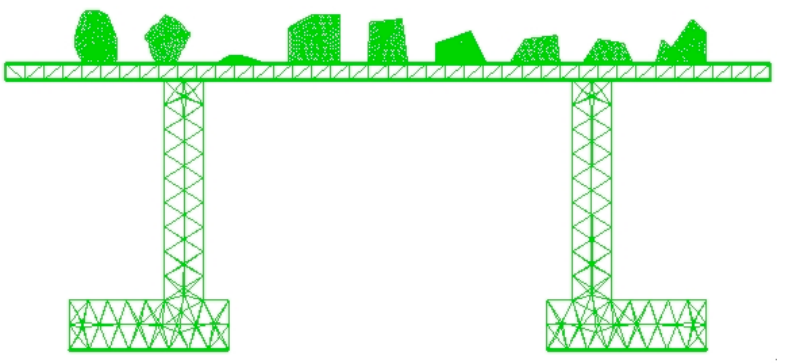

Fig. 10. CFD model of ballast and platform (view of $x-y$ plane)
According to the conditions of wind tunnel laboratory, the FLUENT fluid operating environment can be treated as uncompressible steady turbulent fluid. The thermodynamic temperature is $290 \mathrm{~K}\left(15^{\circ} \mathrm{C}\right)$ as a constant without air compression. More parameters are listed in Table 3.

\begin{tabular}{c|c} 
Table 3. FLUENT parameters in the simulation \\
\hline Parameters & Value \\
\hline Thermodynamic temperature & $290 \mathrm{~K}\left(15^{\circ} \mathrm{C}\right)$ \\
Dynamic viscosity & $1.7894 \mathrm{e}-05 \mathrm{~kg} / \mathrm{m} \cdot \mathrm{s}(\mathrm{Pa} \cdot \mathrm{s})$ \\
Air density & $1.225 \mathrm{~kg} / \mathrm{m}^{3}$ \\
Ballast roughness constant & 0.4 \\
Ballast roughness height & $3 \mathrm{~mm}$ \\
Turbulent viscous & 10 \\
\hline
\end{tabular}

The type of inlet condition was set up by VELOCITY_INLET, and outlet condition OUTFLOW. The wind velocity increased $5 \mathrm{~m} / \mathrm{s}$ per step from $10 \mathrm{~m} / \mathrm{s}$ to $30 \mathrm{~m} / \mathrm{s}$ with corresponding of tests. Fluid solver model was set up as implicit pressure solving method, 3-D, steady time style and absolute velocity. Turbulent fluid model adopted S-A single equation model [9].

Monitoring points were in the middle of windward side on each ballast particles. Static wind pressure was monitored to investigate the initiation of ballast flying and wind pressure.

\subsubsection{Results and Analysis}

In the wind tunnel test simulation, temporal variations of wind pressures were obtained and wind pressure distribution was shown in figures.

Three representative curves are drawn for monitoring points in Fig. 11, which show the development of wind pressure variation. Horizontal axis represents number of iterations. At the beginning of the curves, the wind velocity is $15 \mathrm{~m} / \mathrm{s}$. The curves go up rapidly as the wind velocity increased by $5 \mathrm{~m} / \mathrm{s}$. Compared with half-spherical and flat ballast particle, wind pressure increasing of windward is more obvious on the spherical ballast particle. In the same ballast particle size, the spherical ballast particles have larger masses than flat ballast in general. In the wind tunnel tests, ballast particles with larger mass would move at higher wind speed than lighter ones. So even if wind pressure increases, the spherical and half-spherical ballast would not get affected easily by wind pressure.

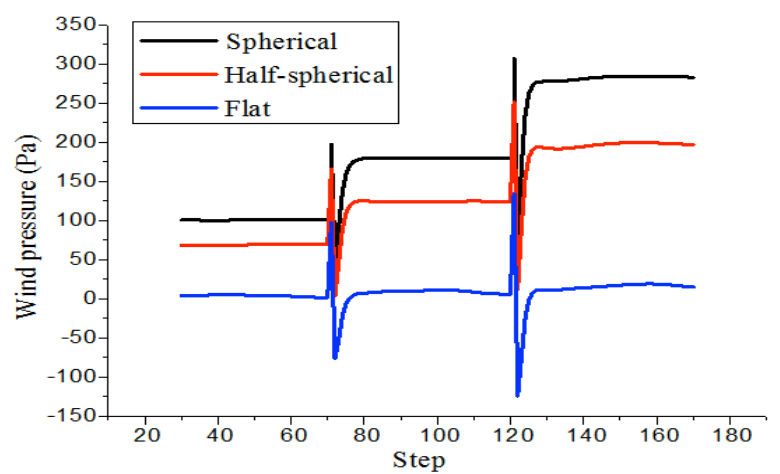

Fig. 11. Wind pressure vs. step

The wind pressure distribution in different wind velocity is shown by Fig. 12. The cold color indicated lower wind pressure and the warm color indicated higher wind pressure. As the picture illustrated, when the wind blows along the 
G.Q. Jing, G.X. Liu, J. Lin, J. Martinez and C.T. Yin

/Journal of Engineering Science and Technology Review 7 (2) (2014) 137 - 142

positive direction on z-axis, the wind force or pressure is not evenly distributed around the ballast particles. In windward side, the wind pressure is $300 \mathrm{~Pa}$, and is the largest within all the exposed surfaces of ballast, which served as thrust in the initiation of ballast flying. Meanwhile, the wind pressure on lee-ward and on the top of ballast appears a low wind pressure. It should be noted that in some area, negative wind pressure values were recorded. The pressure difference plays a significant role in ballast motion phenomenon. If the wind pressure value difference value is large enough, the ballast motion would probably occur. Negative wind pressure areas mostly appear in the back of spherical ballast and half-spherical ballast. If a small ballast particle located in this area, it would probably project under the unbalanced negative wind pressure.

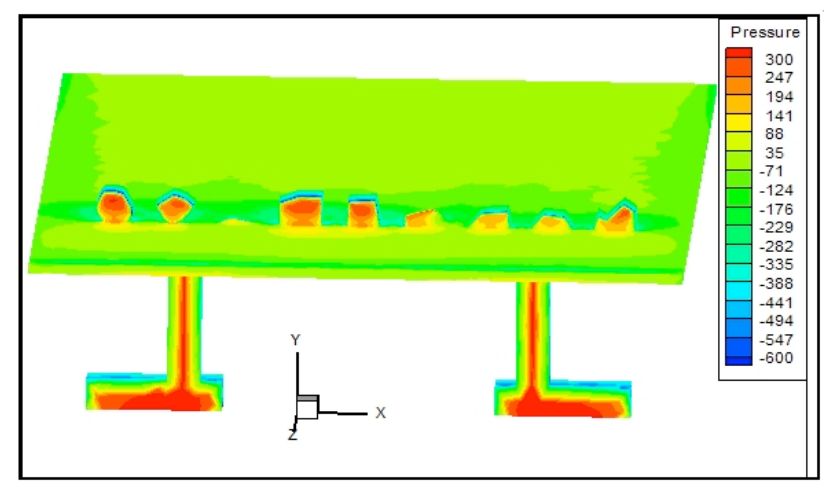

Fig. 12. Wind pressure distribution

\section{Conclusions}

In this paper, the characteristics of ballast aerodynamic effects by wind tunnel were investigated. Two sets of tests and related simulations were performed. Wind tunnel test acts as an important part of the indoor aerodynamics characteristics analysis, and its main objective is listed as following.

The wind fluid velocity and pressure interactions with ballast particles can be determined by wind tunnel tests and CFD simulation, at the same time these parameters influences, such as wind velocity, wind pressure, ballast shape and mass, ballast particle movement on the elevated platform can be observed and analyzed. The conclusions are listed as followed:

(1) The wind tunnel tests show that the wind pressure has a positive proportion with the critical wind velocity especially when the wind velocity is less than $22 \mathrm{~m} / \mathrm{s}$. There are also other factors such as the concave-convex and other factors which need to be further investigated.

(2) In current study, the minimum critical wind velocity at which ballast starts to move is about $8 \mathrm{~m} / \mathrm{s}$. It can be seen that most ballast particles started to move at the wind velocity of $25 \mathrm{~m} / \mathrm{s}$.

(3) The critical wind velocity is influenced by ballast mass, and is less related with ballast particle contact area with the platform surface. And lighter (small) ballast particles usually start to move earlier and farther distance than the bigger ones.

It has become clear that more studies are needed in order to define a measurement procedure for the assessment of trains with respect to ballast projection. Some initial aspects of the ballast projection phenomenon have been studied but we are not yet able to give a comprehensive and exact conclusion.

Future work on the CFD-DEM coupling method will be more instructive, which avoids all the assumptions for building a function which can simultaneously take into account ballast particle velocities and particle physical characteristics, such as the ballast size, surface etc. Even CFD-DEM coupling method calculation cost is very large, but it has visible advantages.

\section{Acknowledgements}

This study has been carried out by support from NSFC (51108026) and Fundamental Research Funds for Central Universities (2014JBM095).

\section{References}

1. G.Q. Jing, Y.D. Zhou, J. Lin, J. Zhang, "Ballast flying mechanism and sensitivity factors analysis", International Journal on Smart Sensing and Intelligent Systems 5(4),2012, pp.928-939.

2. H. B. Kwon, C. S. Park, "Substructure flow analysis and experiments of high speed train for researching the mechanism of ballast dispersion", Proceeding of Korean Society for Railway 2003 fall, 2003, book 3, pp. 275-280.

3. M. Yhshida, M. Uchida, N. Yaguchi, "Countermeasures for ballast-flying phenomena caused by high-speed trains", RTRI Report 6(6), 1992, pp. 27-36.

4. Quinn, Andrew, Mick Hayward, "Full scale aerodynamic measurements underneath a high speed train", Proceedings of the BBAA VI, Milano, Italy, 2008, pp.1-9.

5. Panier F., "Zulassung des ICE 3 in Frankreich-die praktische Erprobung”, Eisenbahn-Revue, 11, 2005, pp. 514-517.

6. Lazaro, Benigno J., Ezequiel Gonzalez, "Characterization and Modeling of Flying Ballast Phenomena in High-speed Train Lines", The ninth world congress on railway research, 2010.
7. H. B. Kwon, C. S. Park, “An experimental study on the relationship between ballast-flying phenomenon and strong wind under high-speed train", Proceedings of the World Congress on Rail Research, Montreal, Canada, 2006.

8. Baker, C., "The simulation of unsteady aerodynamic cross wind forces on trains", Journal of Wind Engineering and Industrial Aerodynamics 98(2), 2010, pp. 88-99.

9. H. J. Kaltenbach, P. E. Gautier, G. Agirre, A. Orellano, K. Schroeder-Bodenstein, M. Testa, Th. Tielkes, "Assessment of the aerodynamic loads on the trackbed causing ballast projection: results from the DEUFRAKO project Aerodynamics in Open Air", Proceedings of the World Congress on Rail Research, Seoul, South Korea, 2008

10. García, Javier, Antonio Crespo, Aitor Berasarte, and Javier Goikoetxea, "Study of the flow between the train underbody and the ballast track", Journal of Wind Engineering and Industrial Aerodynamics 99(10), 2011, pp. 1089-1098.

11. AD Quinn, W.A Powrie, "Full scale experimental and modeling study of ballast flight under high speed trains, Proceedings of the Institution of Mechanical Engineers", Part F:Journal of Rail and Rapid Transit, 224(2),2010, pp. 61-74. 